\title{
FORMAÇÃO INICIAL DE PROFESSORES PARA A EDUCAÇÃO BÁSICA uma (re)visão radical
}

\author{
Guiomar Namo de Mello \\ Diretora Executiva da Fundação Victor Civita e Membro do Conselho Nacional de Educação
}

\begin{abstract}
Resumo: Para que a aprendizagem escolar seja uma experiência intelectualmente estimulante e socialmente relevante, é indispensável a mediação de professores com boa cultura geral e domínio dos conhecimentos que devem ensinar e dos meios para fazê-lo com eficácia. O artigo analisa o sistema brasileiro de formação de professores: apontando sua inadequação para colocar em prática o paradigma curricular requerido pela sociedade da informação e prescrito pela LDB; sugerindo caminhos e estratégias para a construção de modelos de formação; indicando condições mínimas para que os cursos de formação inicial de professores cumpram sua finalidade.

Palavras-chave: formação de professores; educação no Brasil; política educacional.
\end{abstract}

\section{O imaginário popular tem alguma razão quando relaciona a atuação do professor ao irônico dito de G.B. Shaw: "Quem sabe faz, quem não sabe ensina."}

0 ob o pressuposto de que a formação inicial e continuada de professores é a prioridade na educação brasileira no início do século XXI, o presente trabalho pretende contribuir para a necessária mudança no conteúdo e desenho da educação superior de professores para a educação básica. Este estudo reconhece que a formação inicial é apenas um componente de uma estratégia mais ampla de profissionalização do professor, indispensável para implementar uma política de melhoria da educação básica, e finaliza propondo a criação de um sistema nacional de certificação de competências docentes e a priorização da área de formação de professores nas políticas de incentivo, fomento e financiamento.

\section{CONTEXTO: POR QUE É URGENTE REFORMULAR A TEORIA E A PRÁTICA DA FORMAÇÃO DE PROFESSORES NO BRASIL}

Durante os anos 80 e 90, o Brasil deu passos significativos para universalizar o acesso ao ensino fundamental obrigatório: melhorou o fluxo de matrículas e investiu na qualidade da aprendizagem desse nível escolar. Recente- mente, agregam-se a esse esforço o aumento do número de crianças de 6 anos ao sistema educacional e a expansão do ensino médio.

A democratização do acesso e a melhoria da qualidade da educação básica vêm acontecendo num contexto marcado pela modernização econômica, pelo fortalecimento dos direitos da cidadania e pela disseminação das tecnologias da informação, que impactam as expectativas educacionais ao ampliar o reconhecimento da importância da educação na sociedade do conhecimento.

Em resposta a essas expectativas, desde a década de 80 os sistemas de ensino público e privado vêm passando por processos de reforma educacional, em âmbito estadual, local ou mesmo nas unidades escolares. Algumas dessas iniciativas de reforma são mais abrangentes e atingem todos os componentes do processo educativo; outras dirigem-se a apenas alguns deles.

Com a promulgação da Lei no 9.394/96, a nova Lei de Diretrizes e Bases da Educação Nacional (LDB), que incorporou as experiências e lições aprendidas ao longo desses anos, inicia-se outra etapa de reforma. Em relação à flexibilidade, regime de colaboração recíproca entre os entes da federação e autonomia dos entes escolares, a nova LDB consolidou e tornou norma uma profunda ressignificação do processo de ensinar e aprender: prescreveu um paradigma curricular no qual os conteúdos de ensino deixam de ter importância em si mesmos e são entendidos 
como meios para produzir aprendizagem e constituir competências nos alunos.

$\mathrm{Na}$ sucessão da LDB, os órgãos educacionais nacionais estão desenvolvendo um esforço de regulamentação e implementação do novo paradigma curricular. No Conselho Nacional de Educação foram estabelecidas, em cumprimento ao mandato legal desse colegiado, as diretrizes curriculares nacionais para a educação básica. Por seu caráter normativo, as diretrizes são genéricas: focalizam as competências que se quer constituir nos alunos, mas deixam ampla margem de liberdade para que os sistemas de ensino e as escolas definam conteúdos ou disciplinas específicas.

No executivo, o MEC elaborou um currículo nacional - os parâmetros curriculares do ensino fundamental e do ensino médio -, além de referenciais curriculares para educação infantil, educação indígena e educação de jovens e adultos. Todo esse trabalho está disponível, em caráter de recomendação, a todos os sistemas e escolas.

Estados, municípios e escolas estão, por sua conta, adotando as providências necessárias à organização de seus currículos de acordo com o novo paradigma disposto na LDB e nas normas nacionais. Essas iniciativas se beneficiam tanto dos parâmetros e referenciais preparados pelo MEC quanto da assistência técnica de universidades, instituições de estudos e pesquisas e organizações não-governamentais do setor educacional.

A implementação da reforma curricular envolve, e envolverá ainda mais, em diferentes graus, distintos segmentos do setor educacional brasileiro. Devido à complexidade do sistema federativo do país e sua enorme diversidade, esse processo ocorre com muito mais consenso do que dissenso. Duas razões contribuem para a construção desse consenso: o contexto econômico e cultural, que impõe a revisão dos conteúdos do ensino; e a LDB, que atua como fator de coesão. Na medida em que as principais respostas para essa revisão foram contempladas na lei, os vários âmbitos ou instâncias de sua regulamentação e execução estão empenhados em colocá-la em prática.

Se a aprovação da LDB marcou o final da primeira geração de reformas educacionais, as diretrizes e parâmetros curriculares inauguraram a segunda geração, que tem duas características a serem destacadas: não se trata mais de reformas de sistemas isolados mas sim de regulamentar e traçar normas para uma reforma da educação em âmbito nacional; e atinge, mais que na etapa anterior, o âmago do processo educativo, isto é, o que o aluno deve aprender, o que ensinar e como ensinar.
A etapa que ora se inicia, se implementada para atingir suas conseqüências mais profundas, deverá mudar radicalmente a educação básica brasileira ao longo das duas ou três primeiras décadas do terceiro milênio. Para gerenciá-la de modo competente, é preciso que todos os envolvidos construam uma visão de longo prazo e negociem as prioridades.

\section{FORMAÇÃO DE PROFESSORES: DISTORÇÕES E OPORTUNIDADES}

A divisão entre o professor polivalente e o especialista por disciplinas teve na educação brasileira um sentido burocrático-corporativo. Pedagogicamente, não há nenhuma sustentação consistente para uma divisão que em parte foi causada pela separação histórica entre dois caminhos de formação docente: o normal de nível médio e o superior. ${ }^{1}$

Por motivos também históricos, houve um momento, em meados dos anos 70, em que a formação do professor das séries iniciais do ensino fundamental passou a ser feita também em nível superior. Mas, mantendo a segmentação tradicional, o locus dessa formação não foi o mesmo das licenciaturas, e sim os cursos de pedagogia nas faculdades de educação.

A distância entre o curso de formação do professor polivalente, situado nos cursos de pedagogia, nas faculdades de educação, e os cursos de licenciatura, nos departamentos ou institutos dedicados à filosofia, às ciências, e às letras, imprimiu àquele profissional uma identidade pedagógica esvaziada de conteúdo. ${ }^{2}$

Não é justificável que um jovem recém-saído do ensino médio possa preparar-se para ser professor de primeira a quarta série em um curso que não aprofunda nem amplia os conhecimentos previstos para serem transmitidos no início do ensino fundamental. Nem é aceitável a alegação de que os cursos de licenciatura "não sabem" ou "não têm vocação" para preparar professores de crianças pequenas.

É também difícil de aceitar que, para lecionar até a quarta série do ensino fundamental, o professor domine os conteúdos curriculares dessas séries apenas no nível médio, enquanto para lecionar a partir da quinta em diante do ensino fundamental e médio seja necessário um curso superior de quatro anos. Da mesma forma, é raro que os formadores de formadores justifiquem o currículo de graduação das licenciaturas de futuros professores em função daquilo que eles deverão ensinar nos níveis fundamental e médio. 
Na perspectiva de uma educação básica que deverá ser de pelo menos 11 anos e universalizada para todos, essa divisão precisa ser questionada, em busca de uma visão geral da formação do professor da educação básica. Além disso, do ponto de vista legal, é possível existirem professores especialistas desde o início do ensino fundamental, até mesmo na educação infantil. Da mesma forma, é possível existirem professores polivalentes nas séries terminais do ensino fundamental e até no ensino médio. Do ponto de vista pedagógico, essa é uma decisão que deve ser tomada de acordo com o projeto educacional dos sistemas de ensino ou das escolas.

As diretrizes curriculares constantes da LDB e das normas que a regulamentam dão maior ênfase às competências do que às disciplinas, fato que abre amplas possibilidades de organização interdisciplinar, de definição de conteúdos transversalizados que não correspondem a disciplinas tradicionais, de realização de projetos de ensino. Esse paradigma novo vai romper com o modelo disciplinarista que repousa sobre a divisão das licenciaturas no ensino superior.

A localização institucional das licenciaturas na estrutura do ensino superior, e particularmente das universidades, cria um divórcio entre a aquisição de conhecimentos nas áreas de conteúdos substantivos e a constituição de competências para ensinar esses conteúdos a crianças, adolescentes ou adultos com atraso escolar. ${ }^{3}$

O único aspirante ao magistério que ingressa no ensino superior com opção clara pelo ofício de ensinar é o aluno dos cursos de magistério de primeira a quarta série do ensino fundamental. A esses, na maior parte dos cursos, não é oferecida a oportunidade de seguir aprendendo os conteúdos ou objetos de ensino que deverá ensinar no futuro. Aprende-se a prática do ensino, mas não sua substância.

Os demais ingressam no ensino superior de formação de professores com a expectativa de serem biólogos, geógrafos, matemáticos, lingüistas, historiadores ou literatos, dificilmente professores de biologia, de geografia, de línguas ou de literatura. Os cursos de graduação são ministrados num contexto institucional distante da preocupação com a educação básica, que não facilita nem mesmo a convivência com pessoas e instituições que conhecem a problemática desta última. Os professores formadores que atuam nesses cursos, quando estão em instituições de qualidade, são mais preocupados com suas investigações do que com o ensino em geral, e menos interessados ainda no ensino da educação básica.
No caso do professor polivalente, a preparação se reduz a um conhecimento pedagógico abstrato porque é esvasiado do conteúdo a ser ensinado. No caso do especialista, o conhecimento do conteúdo não toma como referência sua relevância para o ensino de crianças e jovens, e as situações de aprendizagem que o futuro professor vive não propiciam a articulação desse conteúdo com a transposição didática; em ambos os casos, a "prática de ensino" também é abstrata, pois é desvinculada do processo de apropriação do conteúdo a ser ensinado.

Para cumprir a LDB na letra e no espírito, será necessário reverter essa situação. A lei manda que o professor de educação básica construa em seus alunos a capacidade de aprender e de relacionar a teoria à prática em cada disciplina do currículo; mas como poderá ele realizar essa proeza se é preparado num curso de formação docente no qual o conhecimento de um objeto de ensino, ou seja, o conteúdo, que corresponde à teoria, foi desvinculado da prática, que corresponde ao conhecimento da transposição didática ou do aprendizado desse objeto?

Enquanto a educação básica é um serviço principalmente do setor público, a formação de professores para a educação básica é realizada com importante aporte do setor privado. No Sul e Sudeste, este é largamente majoritário. Nas demais regiões do país, é apenas expressivo, em virtude da grande presença de instituições de ensino superior estaduais e, em menor número, municipais.

Não há avaliação da qualidade dos resultados desses cursos de preparação docente, sejam eles públicos ou privados, porque a formação de professores tem sido tratada como qualquer outro curso de nível superior, sem considerar seu papel estratégico para todo o sistema educacional do país. ${ }^{4}$ Como os demais cursos superiores, eles são previamente autorizados e reconhecidos. Nunca passaram por avaliação posterior das competências necessárias para formar professores da educação básica brasileira. ${ }^{5}$

Essa situação dá origem a algumas distorções graves: nas regiões em que a oferta de cursos de formação docente é predominantemente privada, o poder público, que mantém a educação básica, garante o mercado de trabalho dos egressos do ensino superior privado sem dispor de mecanismos eficientes de controle da qualidade desses professores; e nas regiões em que os cursos de formação de professores são predominantemente públicos estaduais, o poder público pode financiar com recursos da educação básica a formação de seus professores, o que caracteriza um duplo financiamento das instituições estaduais de ensino superior. 
O problema é ainda maior quando se considera que os sistemas públicos de educação básica, estaduais e municipais, gastam volumes consideráveis de recursos em capacitação de professores, dinheiro anualmente pago às mesmas instituições de ensino superior privadas e públicas para refazerem um trabalho que não foi bem-feito durante a formação inicial dos professores.

A única e importante vantagem do modelo atual é sua sustentabilidade financeira. As grandes universidades públicas federais e estaduais, nas quais o custo aluno é alto, dedicaram-se muito mais, proporcionalmente, às carreiras superiores "nobres" como medicina, engenharia, direito, arquitetura. Entre essas carreiras, nunca foi incluída a formação de professores para a educação da maioria. Por essa razão, há várias décadas os futuros professores, geralmente originários das camadas médias e médias baixas, arcam com os custos da própria formação profissional no setor privado ou recorrem ao ensino superior estadual, quase sempre de custo e qualidade inferiores ao federal ou aos estaduais "nobres".

Diante das demandas de uma reforma educacional como a que se inicia, essa situação pode representar uma oportunidade histórica. Seria inviável para o poder público financiar, pelos preços das universidades "nobres", a formação de seus professores de educação básica, que já são mais de um milhão. Com um volume de recursos muito menor, um sistema misto de custos baixos, tanto públicos quanto privados, configuram-se um ponto estratégico de intervenção para promover melhorias sustentáveis a longo prazo no ensino básico.

No futuro, o país vai precisar de bons professores, que substituam os hoje existentes. Essa necessidade deverá expressar-se num fluxo que a médio prazo vai repor integralmente o plantel docente hoje existente. Toda e qualquer melhoria na formação desse fluxo de mais de 1,5 milhão de professores vai representar um ensino melhor para dezenas de milhões de alunos durante os 25 que durarem a carreira de cada geração de professores.

É urgente investir na organização de um sistema nacional de credenciamento de cursos e certificação de competências docentes radicalmente diferente da atual processualística de autorização e reconhecimento de cursos superiores em geral; apoiar escolas avaliadas e credenciadas, com assistência técnica e financeira; condicionar o exercício do magistério à conclusão do curso em instituição credenciada e à avaliação para certificação de competências docentes.
Medidas dessa natureza teriam custos relativamente pequenos se comparados aos que são necessários para arcar com os ônus do fracasso escolar: recuperação do nível de aprendizagem, aceleração da escolaridade e regularização da matrícula dos milhões de alunos atendidos por professores provenientes de cursos de formação ruins.

No futuro, a boa qualidade dos professores poderá eliminar os custos de organização dos grandes empreendimentos de capacitação ou educação continuada destinados a ensinar àqueles que, se tivessem aprendido a aprender, poderiam ser gestores da própria atualização profissional. Com professores bem preparados, a educação continuada poderia ser quase inteiramente realizada na escola, sem a parafernália dos grandes encontros de massa, que os tornam eventos de interesse maior para a hotelaria do que para a educação.

Os organismos formuladores de políticas, os financiadores de projetos de reforma, as universidades e outras instituições sociais precisam se dar conta e levar a conseqüências práticas esse fato óbvio: no caso brasileiro, o investimento na formação de professores para a melhoria da educação básica pode ser o de melhor rentabilidade ou o de melhor relação custo-benefício. Esse é um cálculo que deverá ser feito principalmente com os estudantes que terão acesso a linhas de crédito para financiar seus cursos superiores.

\section{PROPOSTA DE DIRETRIZES PEDAGÓGICAS: CONSEQÜÊNCIAS DA SIMETRIA INVERTIDA ENTRE FORMAÇÃO E EXERCÍCIO PROFISSIONAL}

A mudança nos cursos de formação inicial de professores terá de corresponder, em extensão e profundidade, aos princípios que orientam a reforma da educação básica, mantendo com esta sintonia fina. Não se trata de criar modismos, mas de buscar modalidades de organização pedagógica e espaços institucionais que favoreçam a constituição, nos futuros professores, das competências docentes que serão requeridas para ensinar e fazer com que os alunos aprendam de acordo com os objetivos e diretrizes pedagógicas traçados para a educação básica.

A educação escolar é uma política pública endereçada à constituição da cidadania. Quando forma médicos, contribui para o sistema de saúde da mesma forma que a preparação de cineastas é a contribuição da educação para o desenvolvimento da arte cinematográfica. Quando se tra- 
ta de professores, a educação está cuidando do desenvolvimento dela mesma, para que possa continuar contribuindo para a medicina, a engenharia, as artes e todas as atividades que exigem preparação escolar formal, além de sua finalidade de constituição de cidadania.

A situação de formação profissional do professor é inversamente simétrica à situação de seu exercício profissional. Quando se prepara para ser professor, ele vive o papel de aluno. O mesmo papel, com as devidas diferenças etárias, que seu aluno viverá tendo-o como professor. Por essa razão, tão simples e óbvia, quanto difícil de levar às últimas conseqüências, a formação do professor precisa tomar como ponto de referência, a partir do qual orientará a organização institucional e pedagógica dos cursos, a simetria invertida entre a situação de preparação profissional e o exercício futuro da profissão. As diretrizes que se seguem procuram avançar nessa característica, buscando tornar coerente a formação do professor com a simetria existente entre essa formação e o futuro exercício da profissão.

Uma conseqüência disso é que a educação inicial de professores deve ter como primeiro referencial as normas legais e recomendações pedagógicas da educação básica. Os professores não são necessários para qualquer projeto pedagógico, mas para aqueles que vão ser executados sob a orientação normativa das diretrizes curriculares nacionais e sob a recomendação dos parâmetros e planos curriculares formulados pelo MEC, pelos sistemas públicos de ensino e pelas escolas particulares. Os modelos ou instituições de formação docente que interessam ao país são, portanto, aqueles que propiciam ou facilitam a constituição de um perfil de profissionais adequados a essa tarefa.

Ninguém facilita o desenvolvimento daquilo que não teve oportunidade de aprimorar em si mesmo. Ninguém promove a aprendizagem de conteúdos que não domina, a constituição de significados que não compreende nem a autonomia que não pôde construir. É imprescindível que o professor que se prepara para lecionar na educação básica demonstre que desenvolveu ou tenha oportunidade de desenvolver, de modo sólido e pleno, as competências previstas para os egressos da educação básica, tal como estabelecidos nos artigos 22, 27, 32, 35 e 36 da LDB e nas diretrizes curriculares nacionais da educação básica. Isso é condição indispensável para qualificá-lo como capaz de lecionar na educação infantil, no ensino fundamental ou no ensino médio.

Muitos dos jovens que hoje saem da educação básica e ingressam no ensino superior não possuem essa condi- ção mínima. É preciso que a formação docente propicie a eles a oportunidade de refazer o percurso de aprendizagem que não foi satisfatoriamente realizado na educação básica para transformá-los em bons professores, que no futuro contribuirão para a melhoria da qualidade da educação básica.

Essa afirmação, aparentemente redundante, tem o objetivo de evidenciar que a formação inicial de professores constitui o ponto principal a partir do qual é possível reverter a qualidade da educação. É como se, ao tocá-la, fosse mais fácil provocar uma reação do sistema total, gerando um efeito em série: um círculo virtuoso de conseqüências mais duradouras.

Assim entendida como componente estratégico da melhoria da qualidade da educação básica, a formação inicial de professores define-se como política pública. Embora não seja necessário que o poder público a execute diretamente, é indispensável que ele estabeleça critérios de financiamento, padrões de qualidade e mecanismos de avaliação e acompanhamento.

Com competências a serem constituídas na educação básica, a formação inicial dos professores para atuarem na mesma educação básica deve levar em conta os princípios pedagógicos estabelecidos nas normas curriculares nacionais: a interdisciplinaridade, a transversalidade e a contextualização, e a integração de áreas em projetos de ensino, que constituem hoje mandados ou recomendações nacionais.

Observe-se que "levar em conta", nesse caso, não significa apenas dar informações sobre contextualização, interdisciplinaridade, transversalidade e outros princípios. A simetria invertida de situações de formação e exercício profissional exige que a aprendizagem do conteúdo dos cursos superiores de formação de professores seja presidida pelos mesmos princípios filosóficos e pedagógicos que a lei manda praticar na educação básica.

Mas o país também precisa de diversidade curricular que dê conta de sua complexidade cultural, social e econômica. Os cursos de formação docente deverão ter também como referência os planos curriculares e os projetos pedagógicos dos sistemas de ensino públicos e privados e, sempre que possível, das próprias escolas. Isso poderá estimular o surgimento de vários modelos de formação de professores, com maior adequação às necessidades e características das regiões e dos alunos.

A consideração radical da simetria invertida entre situação de formação e de exercício não implica tornar as situações de aprendizagem dos cursos de formação do- 
cente mecanicamente análogas às situações de aprendizagem típicas da criança e do jovem na educação média.

Não se trata de infantilizar a educação inicial do professor mas de torná-la uma experiência isomorfa à experiência de aprendizagem que ele deve facilitar a seus futuros alunos, ou seja, um aprender que permite apropriar-se de estruturas comuns abstraindo as diferenças de conjuntura.

É importante reconhecer que a aprendizagem pode ser mais ou menos estruturada, mas não pode ser descontextualizada e compartimentalizada em disciplinas estanques. E essa afirmação é verdadeira tanto para o futuro aluno desse professor como para o estudante de hoje, possível professor da educação básica, que está cursando a formação docente inicial em nível superior. Isso, é claro, apresenta o problema da educação de formadores.

$\mathrm{O}$ isomorfismo tem, portanto, duas conseqüências importantes. A primeira é deixar claro que na formação docente está em jogo uma dupla relação entre teoria e prática. A segunda refere-se ao papel da investigação ou da pesquisa nesses cursos.

Uma das relações entre teoria e prática na formação do professor deve ocorrer na área de conhecimento especializado. Ora, se no futuro será necessário que o professor desenvolva em seus alunos a capacidade de relacionar a teoria à prática, é indispensável que, em sua formação, os conhecimentos especializados que o professor está constituindo sejam contextualizados para promover uma permanente construção de significados desses conhecimentos com referência a sua aplicação, sua pertinência em situações reais, sua relevância para a vida pessoal e social, sua validade para a análise e compreensão de fatos da vida real.

Esse tipo de relação entre teoria e prática, decisiva para o professor, pois ele terá de refazê-la com seus alunos, é relevante para qualquer situação de formação profissional: o aluno da licenciatura em matemática, por exemplo, precisa compreender o significado e a função dos vários anos de cálculo integral a que é submetido, mesmo que não se destine ao magistério da matemática.

Mas há outra relação entre teoria e prática que é específica da formação do professor: a aprendizagem da transposição didática do conteúdo, seja ele teórico ou prático. A prática do curso de formação docente é o ensino, portanto cada conteúdo que é aprendido pelo futuro professor em seu curso de formação profissional precisa estar relacionado com o ensino desse mesmo conteúdo na educação básica.
Isso implica um tipo de organização curricular que, em todas as disciplinas do curso de formação, permita também: a transposição didática do conteúdo aprendido pelo futuro professor; e a contextualização do que está sendo aprendido na realidade da educação básica. Ainda com o exemplo anterior, é imprescindível que o aluno da licenciatura de matemática compreenda qual a relevância do cálculo integral para o ensino da matemática na educação básica.

De acordo com esse princípio, desde o primeiro ano e em todas as disciplinas de uma licenciatura especializada, por exemplo, a de língua portuguesa, o exercício de transposição didática do conteúdo e a prática de ensino deveriam estar lado a lado, ministrados pelo mesmo professor ou por outro que também seja especialista em ensino de língua portuguesa.

A dupla relação entre teoria e prática resulta em dois significados próprios ao papel da pesquisa na formação do professor. O primeiro deles é negativo: a competência para fazer pesquisa pura na área de conhecimento de sua especialidade não é relevante para a formação do professor, ainda que os conhecimentos produzidos pela investigação da área substantiva o sejam, e muito. O segundo significado é positivo: a capacidade de pesquisar dentro da área de especialidade aplicada ao ensino, refletir sobre a atividade de ensinar e formular alternativas para seu aperfeiçoamento é indispensável para o futuro professor. Com isso, compreende-se que os objetos da pesquisa nos cursos de formação docente são o ensino e a aprendizagem do conteúdo dos componentes curriculares da educação básica. Isso faz da transposição didática o campo de estudos por excelência dos cursos de formação docente: partindo dos currículos dos ensinos fundamental e médio que o professor terá de operar, quais são os conhecimentos que ampliam, aprofundam, dão relevância e pertinência aos conteúdos que deverão ser ensinados pelo professor e aprendidos pelo aluno? Para dar aula de ciências da primeira à oitava séries do ensino fundamental, o que um professor precisa saber de química, física ou biologia? Com que profundidade? Com qual enfoque metodológico, de modo a adequar-se ao estatuto epistemológico dessas ciências, aos objetivos que se tem ao ensiná-las na educação básica, que é educação de cidadania e não de especialistas, e à criança e ao jovem que vivem neste mundo de hoje? Uma vez compreendida a transposição didática, quais as escolhas mais sábias para ensinar e aprender os conteúdos transpostos? Eis aí um mundo de questões relevantes que a pesquisa didática não tem abordado no Brasil. 
A insistência com a relação teoria e prática decorre do conceito de competência: competência se constrói em situação; não é "conhecimento de", muito menos "conhecimento sobre", mas é conhecimento que pode ser mobilizado para agir e tomar decisões em situações concretas. Situações da vida real envolvem sempre um componente imponderável e imprevisível. No ensino, isso é mais do que verdadeiro.

Como todos os profissionais, o professor precisa fazer ajustes permanentes em suas ações. Mas o professor, como o médico, o cirurgião, o performer de palco, muitas vezes lida com situações que não se repetem nem podem ser cristalizadas no tempo, aguardando um insight ou discernimento de nova alternativa de ação. Boa parte dos ajustes tem de ser feita em tempo real ou em intervalos relativamente curtos, minutos e horas, na maioria dos casos, dias ou semanas, na hipótese mais otimista, sob risco de passar a oportunidade de intervenção no processo de ensino e aprendizagem.

Além do tempo, que limita a periodicidade dos ajustes, os resultados das ações de ensino são previsíveis apenas em parte. O contexto no qual se efetuam é complexo e indeterminado, dificultando uma antecipação exata do produto. A prática docente não tem a exatidão do experimento científico, e é por essa razão que seu ethos não é o do investigador acadêmico. Ao contrário: ensinar requer dispor e mobilizar conhecimentos para improvisar, intuir, atribuir valores e fazer julgamentos que fundamentem a ação mais pertinente e eficaz possível.

Ensinar é uma atividade relacional: para co-existir, comunicar, trabalhar com os outros, é necessário enfrentar a diferença e o conflito. Acolher e respeitar a diversidade e tirar proveito dela para melhorar sua prática, aprender a conviver com a resistência, os conflitos e os limites de sua influência fazem parte da aprendizagem necessária para ser professor.

Mas ensinar é também uma atividade altamente indeterminada ou altamente determinada por fatores que escapam ao controle de quem ensina. O projeto educativo e a ação cotidiana, a intenção e o resultado na sala de aula, na escola, no sistema e na política educacional sempre guardarão alguma distância, maior ou menor. Ensinar, portanto, exige aprender a inquietar-se e a indignar-se com o fracasso sem deixar destruir-se por ele.

Essas competências traçam o perfil do profissional denominado reflexivo pela literatura recente (anexo): um profissional cuja atuação é inteligente e flexível, situada e reativa, produto de uma mistura integrada de ciência, técnica e arte, caracterizada por uma sensibilidade de artista referida como artistry. A tarefa é um saber-fazer sólido, teórico e prático, criativo a ponto de permitir ao profissional decidir em contextos instáveis, indeterminados e complexos, com zonas de indefinição, o que torna cada situação uma novidade que exige reflexão e diálogo com a realidade.

O profissional reflexivo é também aquele que sabe como suas competências são constituídas, é capaz de entender a própria ação e explicar por que tomou determinada decisão, mobilizando para isso os conhecimentos de sua especialidade. A reflexão, nesse caso, identifica-se com a metacognição dos processos em que o profissional está envolvido nas situações de formação e exercício.

Para a formação do professor, esse aspecto é crucial. A hipótese, nesse caso, é a de que ao compreender o processo de aprendizagem e constituição de competências, o futuro professor estaria mais preparado para compreender e intervir na aprendizagem de seu aluno. Para dar sustentação a esse processo, o futuro professor deveria aprender sobre desenvolvimento e aprendizagem de modo integrado aos demais conhecimentos do currículo de formação docente.

A prática deverá estar presente desde o primeiro dia de aula do curso superior de formação docente, por meio da presença orientada em escolas de educação infantil e ensinos fundamental e médio ou de forma mediada pela utilização de vídeos, estudos de casos e depoimentos ou qualquer outro recurso didático que permita a reconstrução ou simulação de situações reais.

O que hoje se entende por estágio deverá, sempre que as condições permitirem, ser equivalente à "residência" para a profissão médica: a culminância de um processo de prática que ocorre pelo exercício profissional pleno, supervisionado ou monitorado continuamente por um tutor ou professor experiente que permita um retorno imediato ao futuro professor dos acertos e falhas de sua atuação. Idealmente, no caso do professor de ensino público, o estágio poderia corresponder ao período probatório de ingresso na carreira docente, desde que o exame para o curso de formação satisfizesse aos requisitos formais do concurso público.

A importância da prática decorre do significado que se atribui à competência do professor para ensinar e fazer aprender. Competências são formadas pela experiência, portanto esse processo deve ocorrer necessariamente em situações concretas, contextualizadas. Mas é preciso cuidar para que não exista nova fragmentação. O termo prá- 
tica na formação do professor tem três sentidos complementares e inseparáveis. O primeiro sentido refere-se à contextualização, relevância, aplicação e pertinência do conhecimento das ciências que explicam o mundo da natureza e o mundo social; em segundo lugar, identifica-se com o uso eficaz das linguagens como instrumento de comunicação e organização cognitiva da realidade natural e social; em terceiro, a prática tem o sentido de ensinar, referindo-se à transposição didática do conhecimento das ciências, das artes e das letras para o contexto do ensino de crianças e adolescentes em escolas de educação básica.

A competência docente não pode prescindir do domínio em extensão e profundidade de um ou mais conteúdos curriculares previstos para os ensinos fundamental e médio. Deve compreender, aplicar e julgar a relevância, relacionar seus conceitos básicos e, como parte inseparável desse domínio de conteúdo especializado, saber fazer a transposição didática do mesmo para situações de ensino e de aprendizagem da educação básica, o que inclui, além de competências de gerência do ensino e da aprendizagem, discernimento para decidir quais conteúdos devem ser ensinados, em que seqüência e com que tipo de tratamento.

Mas, independentemente de seu conhecimento especializado, é preciso lembrar que o professor em formação cumpriu a educação básica. Dela saiu, espera-se, tendo constituído conhecimentos, competências e habilidades básicas para ser um cidadão produtivo. Cidadania é antes de mais nada um exercício de polivalência. Essa polivalência ele pode e deve transferir para seu exercício profissional, abrindo-se portanto aos conhecimentos das demais áreas curriculares, interagindo com seus colegas para estabelecer relações entre sua especialidade e as outras disciplinas a fim de estar propício a praticar a interdisciplinaridade.

Em outras palavras: uma vez constituída a capacidade de continuar aprendendo e a compreensão do mundo físico e social (objetivos do ensino médio, última etapa da educação básica), o professor deverá saber fazer relações significativas entre os conhecimentos especializados que adquiriu no curso de formação de nível superior e as informações das demais áreas ou disciplinas do currículo da educação básica, trabalhando assim de maneira interdisciplinar e favorecendo em seus alunos a compreensão das relações entre as várias áreas do conhecimento.

Nessa perspectiva abre-se, com as novas diretrizes do ensino médio, uma grande oportunidade de trabalho criativo para os cursos desse nível escolar na modalidade normal. A vantagem dos cursos normais de nível médio é a opção - nem sempre bem aproveitada - de levar os alunos a aprender conteúdos e a aprender a ensinar conteúdos de modo integrado e polivalente. Essa qualidade é que se quer transportada pelo menos para a formação inicial, em nível superior, de professores de crianças de até 10 ou 11 anos de idade. Essa é razão mais forte para chamar essa modalidade de Curso Normal Superior, nome importante porque pleno do significado que tem para a educação o tradicional curso normal.

Se a simetria invertida for levada a sério, a interdisciplinaridade é, em princípio, possível para todos os professores, e assim a resistência à interdisciplinariedade será vencida. Na verdade é muito plausível supor que a sensação de incompetência na especialidade do outro leve o professor a sentir-se ameaçado pelo trabalho interdisciplinar, o que, mais uma vez, recomenda uma etapa básica no curso de formação em que se recuperem ou consolidem os conhecimentos do ensino médio.

O professor polivalente ou especialista, independentemente de sua área de especialidade, deve dominar a língua portuguesa, a matemática, a informática e as linguagens de expressão artística, pelo menos no mesmo grau previsto para os formados na última etapa da educação básica. Deve ser capaz de empregar as linguagens como recurso de auto-aprendizagem e de utilizá-las, em sua atividade docente, como meio de comunicação com o aluno e como recurso capaz de ajudar este último, dentro de sua área de especialidade, a organizar cognitivamente a realidade, construir o conhecimento e negociá-lo com os outros.

Se é aceita a premissa de que o sentido da profissão de docente não é ensinar, mas fazer o aluno aprender, supõe-se que, para que o professor seja competente nessa tarefa, é importante dominar um conjunto básico de conhecimentos sobre desenvolvimento e aprendizagem. Esse domínio deve estar na aplicação dos princípios de aprendizagem na sala de aula; na compreensão das dificuldades dos alunos e no trabalho a partir disso; na contextualização do ensino de acordo com as representações e os conhecimentos espontâneos dos alunos; do envolvimento dos alunos na própria aprendizagem.

A competência implica sempre a articulação de diferentes conhecimentos. No caso do professor, isso significa organizar informações de conteúdo especializado, de didática e prática de ensino, de fundamentos educacionais e de princípios de aprendizagem em um plano de ação docente coerente com o projeto pedagógico da escola; participar da elaboração deste último sabendo trabalhar 
em equipe; e estabelecer relações de cooperação dentro da escola e com a família dos alunos.

A competência docente requer também mobilizar conhecimentos e valores em face da diversidade cultural e étnica brasileira, das necessidades especiais de aprendizagem, das diferenças entre homens e mulheres, de modo a ser capaz não só de acolher as diferenças, como de utilizá-las para enriquecer as situações de ensino e aprendizagem em sala de aula.

O professor competente não se limita a aplicar conhecimentos, mas possui características do investigador em ação: é capaz de problematizar uma situação de prática profissional; de mobilizar em seu repertório ou no meio ambiente os conhecimentos para analisar a situação; de explicar como e por que toma e implementa suas decisões, tanto em situações de rotina como diante de imprevistos, revelando capacidade de metacognição dos próprios processos e de transferência da experiência para outras situações; de fazer previsões, extrapolações e generalizações a partir de sua experiência, e registrá-las e compartilhá-las com seus colegas.

Finalmente, mas sem esgotar a relação das competências a serem desenvolvidas pelos cursos de formação, é importante mencionar que a profissionalização do professor depende de sua competência em fazer avaliações, realizar julgamentos e agir com autonomia diante dos conflitos e dilemas éticos de sua profissão, e de sua capacidade em gerenciar seu próprio desenvolvimento profissional por meio de um processo de educação continuada.

\section{PROPOSTA DE DIRETRIZES INSTITUCIONAIS: DIVERSOS LOCUS, UMA SÓ MISSÃO}

O arranjo institucional adequado para a formação de professores será aquele que conseguir construir, ao longo do curso, o perfil profissional docente que o país necessita para implementar a reforma da educação básica, consubstanciada em suas diretrizes curriculares nacionais, nos parâmetros curriculares recomendados pelo MEC e nas ações de implementação iniciadas por estados e municípios.

É indispensável que os professores em preparação para lecionar nos anos iniciais do ensino fundamental dominem os objetos de ensino: língua portuguesa, matemática, ciências naturais, história e geografia. Portanto, será necessário que o modelo do normal de nível médio seja construído agora como nível superior.

A diversidade curricular e de projetos pedagógicos será bem-vinda, observada essa missão dos cursos de prepa- ração docente. Concretamente, essa missão estará satisfeita se os projetos pedagógicos dos cursos propiciarem que a experiência de aprendizagem dos futuros professores se caracterize segundo os aspectos citados a seguir:

- preparação para lecionar nos anos iniciais do ensino fundamental que inclua o domínio dos objetos de ensino: língua portuguesa, matemática, ciências naturais, história e geografia, pelo menos, o que implicará construir em nível superior o modelo do normal de nível médio aproveitando o conhecimento e a experiência dos formadores de professores que se situam nos cursos de licenciatura tradicionalmente dedicados à formação do especialista;

- currículo de formação em uma (licenciaturas especializadas) ou mais (polivalentes) áreas de conhecimento definido em função das diretrizes curriculares da educação básica e dos currículos recomendados ou dos parâmetros curriculares adotados pelas diferentes instâncias (nacional, estaduais e municipais). A quantidade, seqüência, profundidade da formação do futuro professor em uma ou mais áreas de conhecimento deverão ter como critério aquilo que depois ele terá de ensinar a seus alunos e como deverá ensinar;

- integração permanente e contínua entre teoria e prática desde o início do curso de graduação, em todas as disciplinas do currículo de formação profissional, inclusive naquelas tradicionalmente consideradas "alheias" à formação docente. Essa integração deve ser trabalhada como contextualização dos conhecimentos no mundo social e natural de modo a propiciar situações de aprendizagem significativa aos futuros professores, tanto nas áreas de conteúdo específico como nas áreas de fundamentos educacionais;

- orientação para a pesquisa em ação ou pesquisa aplicada, com ênfase na relação entre teoria e aplicação, tanto dos conhecimentos de conteúdos ou objetos de ensino quanto dos conhecimentos pedagógicos. Mais ainda, ênfase nas investigações sobre os conteúdos ou objetos de ensino e seu ensino a crianças e jovens. Em outras palavras: investigação sobre conhecimento e transposição didática do conhecimento;

- transdisciplinaridade da prática pedagógica e didática pelos demais conteúdos curriculares das disciplinas do curso de graduação para formação de docentes, desde o início do mesmo, para garantir que conteúdos e transposição didática desses conteúdos sejam aprendidos de modo integrado. Quer dizer, contextualização do conhecimen- 
to substantivo do curso de formação do docente, nas situações e problemas da educação básica, sejam elas de ensino e aprendizagem, sejam elas típicas de outras dimensões da vida escolar;

- presença efetiva de disciplinas, recursos, laboratórios ou experiências que assegurem o uso das diferentes linguagens - a língua portuguesa, as linguagens artísticas, a informática, a matemática, as multilinguagens dos meios de comunicação - como recursos de construção do conhecimento no processo de formação profissional do professor;

- relação entre o conhecimento dos princípios que regem o desenvolvimento e a aprendizagem e o processo de construção de conhecimentos de uma ou mais áreas especializadas, de modo a assegurar ao futuro professor uma aprendizagem significativa e aplicada daqueles princípios e uma experiência permanente de metacognição para compreender como ocorre a própria aprendizagem;

- ligação entre as várias áreas que fundamentam o conhecimento educacional a fim de contextualizar essas informações nas situações mais próximas dos futuros professores - a escola de sua comunidade, a escola que freqüentou, a política educacional local e regional -, desenvolvendo compreensão e aplicação de noções sobre a educação escolar, suas relações com a sociedade, a cultura, a vida política e econômica;

- integração entre os diversos campos de ciências humanas e sociais com o objetivo de compreender e aplicar conhecimentos sobre a realidade nacional brasileira, sua diversidade e complexidade social, cultural e étnica, contextualizados por observações reais ou estudos de casos nos quais a questão da diferença é importante, para desenvolver a capacidade de ser pró-ativo na construção de um clima acolhedor das variações e aproveitar a diversidade como recurso de enriquecimento das situações de aprendizagem de seus alunos;

- interdisciplinaridade entre o ensino da didática e as áreas relacionadas à gestão e outros conhecimentos educacionais, a fim de garantir a superação da visão fragmentadora entre gestão e aspectos pedagógicos;

- criação do projeto de formação de professores envolvendo a participação efetiva de escolas ou do sistema escolar público ou privado da região para assegurar:

- a aplicação a situações escolares - reais, simuladas ou mediadas - de todos os conhecimentos que forem adquiridos ao longo do curso de formação do docen- te, não envolvidos diretamente no aprendizado da sala de aula, incluindo atividades de elaboração de projetos pedagógicos, de diagnóstico, proposição e execução de programas, iniciativas de integração da escola na comunidade, prestação de serviços de natureza diversa às escolas da comunidade, trabalhos em equipe envolvendo planejamento, gestão e avaliação de projetos de ensino;

- a existência de um lugar permanente de aplicação dos conhecimentos da didática e da prática de ensino, que envolvem observação, preparação do plano de trabalho docente, regência supervisionada de classes de ensinos fundamental e médio, avaliação, atividades de orientação de alunos, coordenação e animação de trabalho em grupo, entre outras;

- residência escolar com efetiva participação, observação em sala de aula, gerenciamento do tempo e do espaço pedagógicos e dos recursos didáticos de apoio, durante tempo suficiente para enfrentar situações diferenciadas e imprevistas, sempre sob a supervisão da escola onde é realizado o estágio, a qual deverá participar da avaliação final do futuro professor.

- acesso, manipulação e prática com recursos de aprendizagem para si mesmo no curso de formação do docente e com os múltiplos recursos didáticos, tais como: livros, equipamentos, materiais de laboratório, existentes para dar suporte ao trabalho docente na educação básica;

- participação em situações formais ou informais de aprendizagem que ampliem os horizontes da informação, produzam inquietude intelectual e facilitem o acesso à cultura acumulada, às manifestações culturais, aos dados sobre fatos e tendências do mundo contemporâneo e do comportamento individual e social, e sobre o desenvolvimento de tecnologias, a economia e a política no futuro professor;

- conhecimento das condições de trabalho e carreira para ser capaz de compreender e atuar de modo autônomo frente aos conflitos, impasses e dilemas éticos próprios da profissão de docente e do processo educacional em geral;

- assistência para a formulação e execução de um projeto de desenvolvimento profissional durante o curso de formação do docente e para a proposta de um plano de autogestão do desenvolvimento profissional por meio de educação continuada após a conclusão do curso de formação do docente; 


\section{POR UM SISTEMA NACIONAL DE CERTIFICAÇÃO DE COMPETÊNCIAS PARA PROFESSORES}

Além do componente curricular propriamente dito, que diz respeito à organização pedagógica do curso de formação, é indispensável que o país pense ou repense os critérios de autorização dos cursos e de avaliação dos formandos e dos professores já em exercício.

Essa política precisa ser de âmbito nacional, como são e devem continuar sendo os processos de autorização e avaliação de cursos. Como toda política federativa brasileira, é indispensável que ela seja liderada pela União e formulada com a participação dos diferentes níveis interessados.

Vale dizer que uma política nacional de formação de professores precisa ancorar-se em consensos construídos com organismos normativos como o CNE e em coordenação de políticas como o Consed e a Undime, além das agências formadores e das representações não-sindicais do setor educacional e outros segmentos sociais interessados.

O primeiro ponto sobre o qual deverá ser estabelecido o consenso refere-se ao caráter nacional da formação de professores. Só uma coesão firme em torno da formação dos docentes como interesse da nação poderá dar significado pleno, forte e eficaz às diretrizes, referenciais ou recomendações sobre o currículo e a organização pedagógico-institucional dos cursos de formação.

O segundo ponto de consenso deverá ser o credenciamento de cursos e certificação de competências. ${ }^{6}$ É preciso que fique claro que, se a formação do professor deve ser uma política nacional, o credenciamento e a certificação também devem estar nesse âmbito, uma vez que os diplomas expedidos têm validade para todo o país. Esses acordos é que darão legitimidade às diretrizes curriculares e a qualquer proposta de avaliação de cursos ou egressos que venha a ser formulada. Independentemente do desenho específico desses componentes da política, tais acordos têm diversos significados: o país reconhece que a formação de professores precisa com urgência ser considerada uma política da União, como uma das prioridades da reforma e melhoria da educação básica. Como interesse nacional, terá de ser detalhada e implementada por organismos próprios, com participação indispensável das instituições formadoras, mas também dos gestores educacionais públicos e privados das três esferas responsáveis pela provisão de educação básica; uma vez estabe- lecido um padrão de qualidade nacional, ninguém poderá ser professor se seu desempenho revelar competências profissionais inferiores ao padrão nacional; as diretrizes curriculares terão de assegurar princípios de organização pedagógica e curricular comuns para todo o país, qualquer que seja a região, o locus institucional ou a esfera federativa em que ocorra, aí incluídas as universidades, que, em sua autonomia, poderão dar cursos de formação de docente, mas que, no exercício do magistério, terão de oferecer aqueles que cumpram as diretrizes curriculares nacionais.

O desenho e a implementação de um sistema desse tipo requerem investimentos financeiros e técnicos e fontes permanentes de financiamento que assegurem regularidade, transparência e independência das agências ou dos organismos avaliadores. Mas os benefícios resultantes na educação básica com procedimentos tecnicamente sustentáveis, institucionalmente transparentes e politicamente estáveis de avaliação de cursos e competências de formandos nos cursos de formação de docentes compensam os investimentos necessários.

O maior benefício seria assegurar formação de melhor qualidade para os professores da educação básica das próximas décadas, dentro de princípios legais, diretrizes normativas e recomendações nacionais e estaduais. Com isso, pode-se esperar não só a melhoria da qualidade, como também a plena implementação da reforma da educação básica que se está iniciando.

Um benefício secundário, mas significativo, seria eliminar do país os cursos de péssima qualidade e grande procura por parte de alunos que buscam a certificação fácil. A conclusão de cursos desse tipo, que poderiam até continuar existindo, não teria validade nem para a obtenção do diploma, nem para a obtenção de registro ou outra forma de autorização do exercício profissional.

Um impacto mais controverso seria promover a seleção natural das instituições privadas e públicas que têm vocação e disposição para formar professores com seriedade e qualidade, e disponibilizar para essas instituições suporte financeiro e técnico que lhes permitisse alcançar esse objetivo ou aperfeiçoar seus resultados por meio de um sistema mais competitivo de acesso aos recursos.

Reconhecem-se tanto os riscos reais de um sistema desse tipo quanto os fantasmas ideológicos que povoam o armário de velharias das hostes educacionais. Mas é inevitável perguntar se o receio de adotar uma solução tão evidente não é maior que os impasses políticos que ela causaria. Um país com um sistema de formação do 
docente de má qualidade, cuja única vantagem é a sustentabilidade financeira, precisa colocar a iniciativa privada para trabalhar pela educação básica de melhor qualidade.

Do ponto de vista político, o processo de acordo sobre as diretrizes de formação podem servir de estímulo para a discussão - quem sabe mesmo algum novo acordo sobre planos de carreira. Esse assunto ainda não se esgotou no país, e o problema do excesso de formalismo continua existindo na definição de planos de carreira nos quais títulos formais e tempo de serviço terminam tendo maior peso para promoção e melhoria salarial do que resultados obtidos na escola e com os alunos.

Na educação profissional, a certificação de competências é considerada uma resposta para a velocidade da mudança nos processos e nas formas de organização do trabalho. Pode ser levada em conta para o ingresso e o percurso no mercado de trabalho, avaliando a flexibilidade e a laborabilidade ao longo do desenvolvimento profissional, quando existem exigências de periodicidade para certificar novas competências ou recertificar as já constituídas. No caso da carreira docente, esse processo poderá ser de grande impacto para aferir a atualização e a educação continuada do professor e, ao mesmo tempo, impor parâmetros para o ingresso, a progressão na carreira e a remuneração do docente.

Numa proposta mais ousada, o curso de formação e o processo de certificação de competências poderiam ser considerados, a exemplo do que ocorre nos IUFM ${ }^{7}$ franceses, estágios iniciais ou probatórios da própria carreira docente, com remuneração inicial ou não. Uma vez em operação um sistema nacional de credenciamento de cursos e certificação de competências com legitimidade e credibilidade, nada impediria que sistemas estaduais ou municipais adotassem os resultados produzidos nesse processo para organizar seus planos de carreira e até mesmo de ingresso, respeitadas, é claro, as exigências legais.

\section{PRIORIDADE À FORMAÇÃO DE PROFESSORES NOS SISTEMAS DE FOMENTO E FINANCIAMENTO}

A melhoria qualitativa da profissionalização do professor da educação básica deve incluir ainda, além da formação inicial e da certificação de competências, mecanismos que priorizem a área de formação do docente nos programas de crédito educativo para estudantes, fomento de estudos e pesquisas, estudos pós-graduados no país e no exterior.

Para implementar essas prioridades, no entanto, é preciso dispor de critérios claros, consensuais e objetivos. No que diz respeito ao fomento de estudos e pesquisas, é preciso estimular linhas de investigação, bolsas de estudo no país e no exterior, programas de pós-graduação ou de pesquisa, que focalizem o ensino como objeto de estudo. Tudo isso tem de estar articulado com as diferentes áreas do conhecimento, não com a pedagogia ou não apenas com esta última.

Como já foi observado, a investigação didática - entendida em seu sentido mais literal, como o estudo das relações entre o domínio de um campo de saber e o ensino desse conhecimento a crianças e jovens que precisam construir sua cidadania e identidade - é uma temática inexplorada na pesquisa educacional brasileira.

É preciso cobrar dos estudos pedagógicos que não limitem seu objeto de pesquisa à atividade do aluno e do professor, sem um sólido quadro teórico que leve em conta qual é e qual deve ser o conteúdo do ensino e, portanto, o conteúdo da formação do professor e da aprendizagem do aluno. Esse viés, responsável por um ativismo pedagogista que ilusoriamente induz a pensar que o ensino é moderno porque "ativo", baseia-se num conceito limitado da didática. De fato, desde Erasmo na Idade Média, didática não é a escolha do método ou técnica de ensino, ainda que essa etapa final seja muito importante, mas o que a antecede: o estudo da relação entre aquilo que o professor sabe ou deve saber e aquilo que precisa ser aprendido pelo aluno.

No Brasil, está bastante disseminada a concepção de que o conhecimento se constrói, e se constrói em situações socialmente determinadas. Essa teoria, que é em princípio benéfica para a educação, não deve, no entanto, substituir os estudos sobre como se organiza a situação de aprendizagem para que o aluno construa ou reconstrua o conhecimento. A ausência dessa segunda parte leva à falsa noção de que a situação de ensino precisa ser desestruturada ou inestruturada para ser construtivista, o que seria a negação da didática.

No que diz respeito ao crédito educativo, a prioridade para os alunos que se dirigem ao magistério já é uma política adotada pelo MEC. Falta a ela, entretanto, um sistema de credenciamento dos cursos que condicionem o crédito educativo àquelas instituições públicas e privadas que satisfaçam os padrões básicos de qualidade definidos pelo acordo entre as diferentes instâncias educacionais. 


\section{NOTAS}

E-mail da autora: guiomar@uol.com.br

Redigido em junho 2000.

1. Não foi por acaso que a essa segmentação correspondeu uma de gênero, fazendo do magistério das séries iniciais do ensino fundamental uma atividade quase apenas feminina.

2. Embora existam exceções, a crítica se aplica à maioria dos cursos ou programas de educação inicial de professores.

3. Essa não foi a opção de muitos países europeus e latino-americanos. Nestes últimos, os Institutos de Formação Docente, como são comumente conhecidos no Uruguai, na Argentina, no Chile, entre outros, ou as Escolas Normais Superiores, tais como existem até hoje no México, foram as instituições encarregadas de formar professores de crianças e adolescentes. Diga-se mesmo que esse modelo institucional, no caso da França, existe não apenas para professores, como para outras áreas profissionais, como administração, engenharia, medicina, ficando reservada à universidade a preparação de cientistas, filósofos, mestres de letras com ênfase na investigação científica, como, aliás, foi a inspiração da Faculdade de Filosofia, Ciências e Letras no Brasil, primeiro locus institucional de ensino superior responsável pela formação de professores, que se retalhou em departamentos com a Lei no 5.540/68.
4. Só em 1999, o Inep realizou o Exame de Avaliação de Cursos (Provão) em algumas licenciaturas.

5. Em muitas ocupações, os organismos que controlam o exercício profissional procuram zelar, a seu modo, pela qualidade dos cursos de formação. É o caso da Ordem dos Advogados - OAB e dos Conselhos Regionais de Medicina e de Engenharia - CRMs e Creas. Alguns chegam mesmo a fazer exames para autorizar a prática da profissão que representam. O tamanho, a complexidade e a fragmentação do setor educacional impediram a existência desse tipo de controle de qualidade de cursos e formados, feita por órgãos profissionais. Pela natureza do trabalho docente, o exame de seu exercício na educação básica constitui atividade que precisa de maior atenção do poder público, pois é o setor governamental quem absorve a maior parte dos professores formados nos ensinos médio ou superior.

6. Essa expressão não se refere a nenhuma proposta de modelo para o Brasil, uma vez que é algo novo a ser discutido e consensuado. A expressão credenciamento é uma tentativa de tradução do termo accreditation, tal como usado pelo National Council of Accreditation of Teacher Education (NCATE). Já o termo certificação de competência foi tomado do parecer que estabelece as diretrizes curriculares para a educação profissional e pode referir-se ao tipo de atividade desenvolvida pelo National Board of Professional Teaching Standards (NBPTS) e outros órgãos semelhantes, como o Office of Standards in Education (OFSED), da Inglaterra.

7. Instituts Universitaires de Formation de Maîtres. 